\section{Medical Principles} and Practice

\author{
Peter N. Campbell \\ Department of Biochemistry and \\ Molecular Biology, University \\ College London, UK
}

\title{
Bovine Spongiform Encephalopathy (BSE) - Mad Cow Disease
}

\author{
Key Words \\ Prion \\ Scrapie \\ Bovine spongiform \\ encephalopathy \\ Mad cow disease \\ Creutzfeldt-Jakob disease
}

\begin{abstract}
The background to the epidemic of bovine spongiform encephalopathy (BSE) among cattle in the United Kingdom is described as the possible origin of the disease and its relationship to scrapie in sheep. Although the epidemic in cattle is virtually over there is evidence of the transmission of the infectious agent to humans to produce a new variant of Creutzfeldt-Jakob disease. The current status of our understanding of the molecular biology of the infectious agent is described as is the evidence in support of the protein-only, prion, hypothesis. Study of the glycoforms of the prions supports the view that BSE has been transmitted to humans.
\end{abstract}

\section{Introduction}

Until 1985 there were probably not many biochemists in the UK who were more than vaguely aware that sheep tended to suffer from a degenerative disease known as 'scrapie'. Moreover, since the disease had existed in the UK for some 200 years and no one had suggested that it could be transmitted to humans the subject was hardly a prominent one for research. Nevertheless, the British Government did continue to finance research at a modest level in order to unravel the nature of the infective agent, often described as a 'slow

\begin{tabular}{ll}
\hline KARGER & (1998 S. Karger AG, Basel \\
Fax +4161306 12 34 & 1011-7571/98/0073-0172\$15.00/0 \\
$\begin{array}{l}\text { E-Mail karger@karger.ch } \\
\text { www.karger.com }\end{array}$ & $\begin{array}{l}\text { Accessible online at: } \\
\text { http://BioMedNet.com/karger }\end{array}$
\end{tabular}

virus', and similar work was pursued in other countries, especially the USA.

All this changed following the report in 1985 from a farm in Kent, that they had a cow suffering from what is now called 'mad cow disease'. After a delay of about a year before the full significance of the finding became apparent, the situation rapidly changed. We have witnessed a biological problem of mammoth proportions which has many implications in terms of the aetiology of the disease and the nutrition of animals and humans. Although most of the troubles have been centred in the UK there have been a small
Dr. Peter Campbell
Department of Biochemistry and Molecular Biology
University College London
Gower Street
London, WC1E 6BT (UK) 
Table 1. The occurrence of transmissible dementias in about 1985

\begin{tabular}{ll}
\hline Species & Name of dementia \\
\hline $\begin{array}{l}\text { Sheep } \\
\text { Humans }\end{array}$ & $\begin{array}{l}\text { scrapie } \\
\text { kuru in New Guinea } \\
\text { Creutzfeldt-Jakob disease (CJD) } \\
\text { Gerstmann-Straussler-Scheinker disease (GSS) } \\
\text { fatal familial insomnia } \\
\text { bovine spongiform encephalopathy (BSE) }\end{array}$ \\
\end{tabular}

number of cases in Switzerland, but the important point is that the story has implications on a world-wide basis. As I will show, the research effort to understand the problem has been international.

I will start by describing the epidemiology of 'bovine spongiform encephalopathy' (BSE) in the UK and then survey the state of research aimed at understanding the aetiology of the disease and the evolution of possible therapies. I cannot provide in the limited space available a comprehensive list of references. Two books $[1,2]$ give a useful background, an update by the Royal Society [3] which is authoritative, and a review provides older references [4]; in addition I have provided some references to key findings.

\section{Epidemiology}

\section{The Incidence of Transmissible}

\section{Encephalopathies}

The situation concerning the occurrence of the transmissible encephalopathies in the early 1980 s is summarised in table 1 . Scrapie in sheep is characterized by an irritation of the skin caused by damage to the neuronal cells, which causes the animals to rub against a fence or wall in the later stages of the clinical condition, and hence its name. While there are sporadic outbreaks of scrapie in many countries, including Europe and North Amer- ica, it is no longer present in Australia or USA, some breeds being very resistant. Scrapie could be transmitted to other sheep by intracranial injection of infected brains but more significant was the transmission to other species such as goats. After the first passage to a goat there was a long incubation period and this became shorter on further transmission to other goats. This so-called 'species barrier', whereby the clinical symptoms of the disease take longer to emerge when the recipient is of a different species from that of the donor, is an important characteristic of the disease. The length of the incubation period is related to the evolutionary gap between the donor and recipient. In 1961 it was shown that the disease could be transmitted to mice with a much shorter incubation period and more certain outcome and they, therefore, became a favourite test animal. The Syrian golden hamster has also proved to be a useful experimental animal particularly in the hands of Prusiner in San Francisco. In humans Zigas and Gajdusek discovered a disease named 'kuru' among the Fore tribe in New Guinea. They showed that this was spread as a result of a cannibalistic feast involving ritual consumption of their dead relatives. The custom has died out but even today, some 30 years after the practice of cannibalism was suppressed, about 10 people a year die from kuru. The explanation of kuru was that by chance someone suffering from Creutzfeldt-Jakob disease 
Table 2. The chronology of the BSE epidemic

\begin{tabular}{|c|c|c|}
\hline 1985 & (Apr) & BSE first observed clinically \\
\hline 1986 & (Nov) & Disease identified as spongiform encephalopathy \\
\hline 1987 & (Apr) & Initial epidemiological studies started \\
\hline 1987 & $(\mathrm{Dec})$ & $\begin{array}{l}\text { Initial epidemiological studies incriminate ruminant-derived MBM as a } \\
\text { cause of BSE }\end{array}$ \\
\hline \multirow[t]{3}{*}{1988} & (Apr) & Southwood Committee set up \\
\hline & (July) & Ruminant feed ban introduced for MBM \\
\hline & (Aug) & All cattle with symptoms of BSE to be slaughtered \\
\hline \multirow[t]{2}{*}{1989} & (Feb) & $\begin{array}{l}\text { Southwood report; risk to humans 'remote'; estimates expected number of } \\
\text { cattle with BSE to reach } 17,000-25,000\end{array}$ \\
\hline & (Nov) & Ban on use of certain bovine offals for human consumption \\
\hline \multirow[t]{4}{*}{1991} & (Mar) & EU bans export of British cattle over 6 months old \\
\hline & (Apr) & EU bans export of British offal \\
\hline & (May) & First case of 'BSE' in cat \\
\hline & (Sept) & Offal banned from animal feed \\
\hline 1992 & & BSE epidemic peaks at 36,681 cases in a year \\
\hline 1993 & (July) & 100,000 th confirmed case of BSE \\
\hline 1994 & (Nov) & $\begin{array}{l}\text { Thymus and intestines added to offal ban; all mammalian protein banned } \\
\text { from cattle and sheep feed }\end{array}$ \\
\hline 1995 & (Nov) & First 3 deaths of younger humans \\
\hline 1996 & $\begin{array}{l}\text { (Mar) } \\
\text { (July) }\end{array}$ & $\begin{array}{l}\text { Suspected link between BSE and nvCJD; EU bans all British beef exports } \\
\text { Controls on slaughter of sheep }\end{array}$ \\
\hline 1997 & (Dec) & $\begin{array}{l}\text { Ban on sale of beef on the bone because of infectivity in spinal cord and } \\
\text { possibly in bone marrow }\end{array}$ \\
\hline
\end{tabular}

(CJD), which as I will explain is a nervous disease occurring sporadically all over the world, appeared among the Fore people. When the affected person died the surviving relatives became infected. In view of research associated with scrapie, Gajdusek inoculated chimpanzees and other primate species with suspensions of kuru brains. The chimpanzees succumbed after about 1.5 years. Gajdusek was awarded the Nobel prize in 1976.

In addition to CJD, which I will refer to again later, there are two other diseases in humans with a rather similar pathology, namely Gerstmann-Straussler-Scheinker disease (GSS) and fatal familial insomnia. It was in 1985 that the first reports were received of a dementia in cows from farms in England. Although there was some delay in clearly recognizing the disease it became known as 'bovine spongiform encephalopathy' (BSE) in view of the spongy appearance of sections of the brains of the dead animals.

\section{The Chronology of the Epidemic of BSE}

The number of cases of BSE rose dramatically and investigations of the cause were set up. The critical dates in the unravelling of the epidemic are given in table 2. Suspicion centred on a high protein dietary supplement prepared from meat and bone meal (MBM) from sheep and cattle that were not suitable for human consumption. MBM was particularly used for feeding to high milk-yield dairy cows. This is a common practice in many countries. It transpired that for various reasons the method of preparation of MBM in the UK had been changed around 1980 in that the hydrocarbon extraction of fat had 
been reduced and the additional steam treatment that was used to remove the solvents for reuse was omitted. A ban on the use of MBM as a feed for cattle and sheep was rapidly instituted (1988). In 1988 a working party under Prof. Southwood was set up. They made some interim recommendations during 1988 and issued a final report in 1989. The same year they confirmed the suspicion concerning MBM, and recommended that all affected cattle be destroyed. At that time it was suspected that the trouble was caused by scrapie from infected sheep being transmitted to cattle via MBM but as I will show this now seems unlikely. (Moreover, it has not been clearly shown that scrapie can be transmitted to cattle.) Since scrapie had been known for some 200 years and had never been shown to be transmitted to humans, the Southwood Committee reported that although transmission of BSE to humans was possible and could not be ruled out, the chances of it happening were 'remote'. The British Government took up this advice which was a relief to the farmers, and the general picture was that humans were safe from BSE especially since measures had been taken to ban the use of MBM for cattle and sheep although not for pigs and chickens (this did not come until 1996; the delay probably caused some problems in that the manufacturers of MBM did not realise how important it was to disinfect their machinery and some of the still suspect MBM meant for poultry probably was fed to cattle). Soon after, the human consumption of brain, spinal cord and other offal was banned and slaughterhouses were told to remove all spinal cords. Because the chance of transmission to humans was regarded as remote it is clear that some of the recommended precautions were regarded merely as 'window-dressing' and were not fully implemented.

The number of cases of BSE rose dramatically as shown in figure 1 [5], the final total

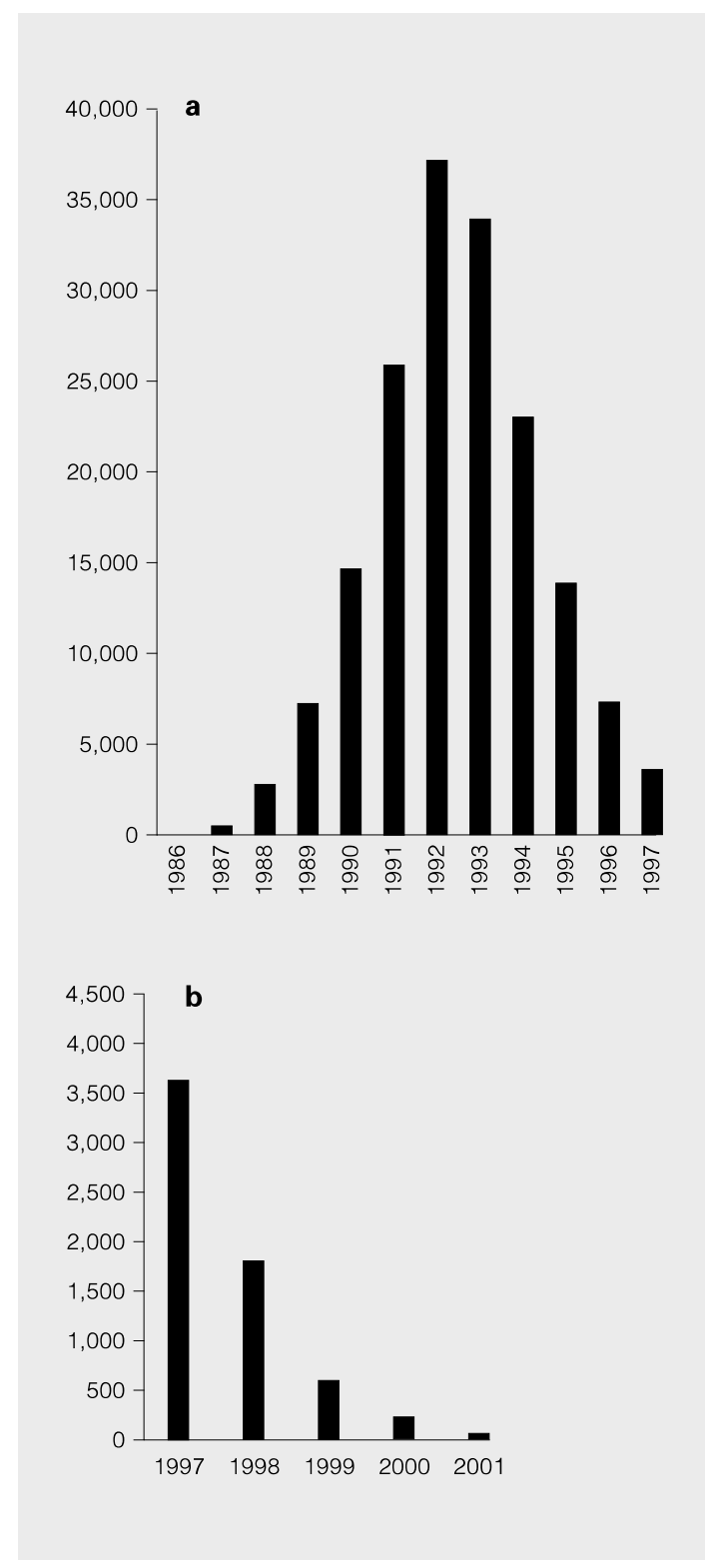

Fig. 1. Number of cases by year of clinical onset of BSE. a From 1986 to 1997, the latter number $(3,592)$ involving some estimates. b The predictions of cases by year for 1997-2001 assuming no selective cull is implemented. A further cull would be expected to reduce the numbers further. 
being about 180,000 . It is estimated that about 1 million cattle have been infected in the UK with several hundred cases in Switzerland and a few elsewhere. In addition to the slaughter of animals showing symptoms there has been the slaughter of older but apparently healthy animals in affected herds so that in all some two million cattle will have been slaughtered. The British Government has had to pay a compensation to the farmers which has cost more than a billion pounds sterling. It is estimated that about 54,000 infected animals have entered the human food chain. This calculation takes into account the large number of infected animals even after the implementation of the ban on MBM. The measures taken to control BSE in cattle have been successful and it is slowly dying out. In 1998 it is predicted that there will be 1,714 cases, with 641 in 1999 and 235 in the year 2000. Such estimates in the past have had a good record of accuracy. There is some evidence of maternal transmission when birth is close to the onset of BSE in the mother but the level of its occurrence is unlikely to be able to sustain the epidemic.

\section{Transmission of BSE to Other Species Including Man}

After 1987, cases of BSE appeared in various other species of animals, particularly among the various ungulates in the zoos and also a few cases among cats (from 1991). The incidence in cats caused particular concern for it was the first case of transmission to a meat-eating animal rather than a herbivore. This strengthened the concern about the possible transmission to humans. Concerning CJD, apart from kuru three different kinds can be discerned: First, there is the 'sporadic' which is the most common and affects individuals, usually in later life, for no known reason. Those affected reside world-wide and there has been no evidence of a recent epi- demic in the UK. Second, the 'familial', this is an autosomal dominant disease which is rather rare. A good deal of genetic work has been done to understand this. Third, the 'iatrogenic' which has been caused by the administration of growth hormone preparations made from a pool of 3,000 cadaver brains in the USA to children with problems of growth. There has been the emergence of CJD in children as a result of such treatment in several countries. In the UK, 1,908 children were treated and there have been 10 cases of CJD. The incidence of the various kinds of CJD in the UK is shown in figure 2. We can conclude that until 1995 the incidence of CJD in the UK was comprehended in terms of the international scenario.

Later a different kind of CJD was to emerge. In August 1995 the first young person, then aged 19, died of CJD followed by several others who were aged about 29 . The brains of these patients had a pathology which closely resembled that of cattle with BSE and was quite different from those who had died of sporadic CJD. In March 1996 when 10 young people had died of CJD the British Government took the advice of its scientific advisory committee that we were witnessing the emergence of a 'new variant' of CJD (nvCJD) and that it seemed likely that this had arisen by the transmission of BSE as a result of the consumption of infected beef. There was also the worry that farm workers were particularly susceptible when the deaths of 3 farmers from CJD were reported. It was subsequently shown that the incidence among farmers was no higher in the UK than elsewhere and subsequent scientific work has discounted this particular concern, for the farmers had not died of nvCJD. In view of the long incubation period of 5-10 years for nvCJD, based largely on the assumption that the greatest chance of people eating infected beef was between 1980 and 1988 when the ban on 


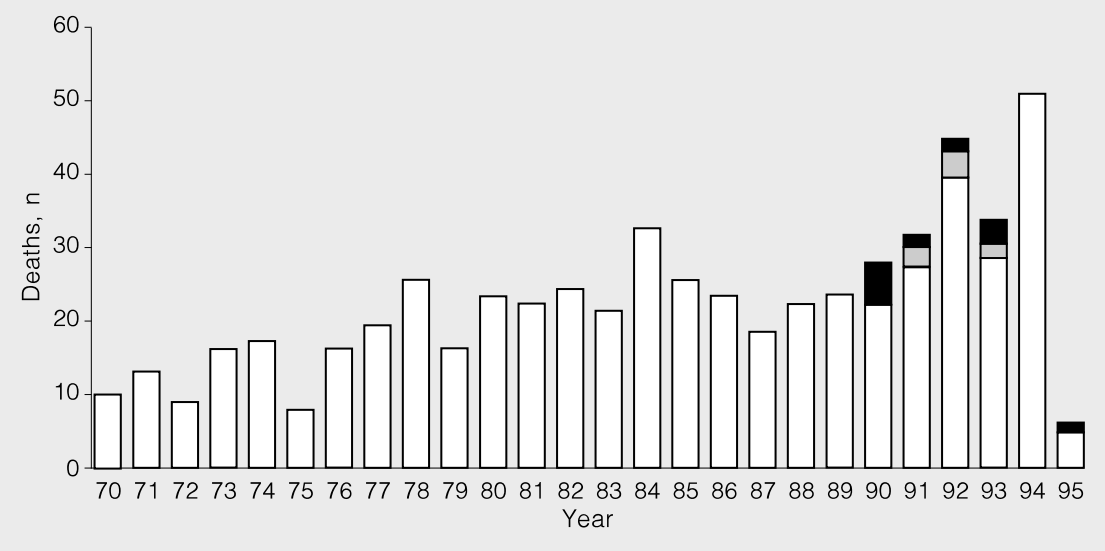

Fig. 2. Deaths from CJD in England and Wales 1st January 1970-30th April 1995. $\square=$ Sporadic; $\square=$ familial; $\square=$ iatrogenic.

MBM was instituted, no sound estimate could be given of the likely scale of the epidemic of nvCJD, but the possibility was mentioned that it could run into thousands of cases. Fortunately, so far the worst predictions have not been fulfilled since the number of new cases is about 1 per month with a total to date of 23 . All the cases except 1 are in the UK, the exception being in France.

\section{The Possible Origin of BSE}

I have indicated above that initially the cause of BSE was thought to be the transfer of scrapie to cattle. More recently it has been shown that BSE can be experimentally transferred to sheep who then show symptoms more akin to those of BSE than scrapie. Thus scrapie and BSE are two different diseases. BSE in cattle and nvCJD in humans bear the hallmarks of BSE rather than scrapie and I will mention scientific evidence to support this view. Thus it now seems more likely that BSE arose as a result of an unusual event - the mutation in a cow which developed BSE and that this cow was used for the manufacture of MBM which was fed back to cattle. The aetiology seems similar to that ascribed to kuru.

\section{More Recent Precautions}

Although no wild sheep has been found with BSE the possibility exists that some will be found so that in the meantime sheep brains and if possible spinal cord, which is difficult to dissect, have been banned for human consumption. Although the neuropathologies do not have an immunological pathogenesis there is evidence that the immune system is important for transporting infection from the periphery to the brain [6]. Mice that are genetically immunodeficient (either SCID mice or RAG knockout mice) cannot be infected by peripheral injection with the infective agent but can be so infected by injection directly into the brain. The prospect has been mentioned of removing white cells from blood before administration but this would be ex- 
tremely difficult and expensive. Blood taken from donors will not in the future be pooled. Pooled blood has been used as a source of serum albumin used in various vaccines. For this reason serum obtained from pooled blood in Britain is no longer being used for the preparation of medical products. In the meantime the message is that blood must be considered 'dirty' unless it is your own.

\section{Experiments to Discover the Nature of the Infective Agent}

\section{Some Characteristics of the Agent}

Following the discovery in 1961 that the scrapie agent could be transmitted to mice, rapid progress was made in determining the characteristics of the infective agent. The agent was resistant to formalin and seemed to have the size of a small virus, e.g. the picornavirus. However, the results of irradiation indicated that the scrapie agent was much smaller than any known virus and corresponded more closely to plant viroids which only contain RNA but unlike them the agent was resistant to nucleases. These were major findings and to the present day no one has been able to demonstrate that a nucleic acid is associated with the infectivity of the scrapie agent. Another important characteristic of the scrapie agent was its resistance to heat. Thus infectivity was retained even if the brain was boiled but infectivity was destroyed at temperatures above $121^{\circ} \mathrm{C}$. No doubt this finding is relevant to the changes in the method of preparation of MBM.

Prusiner [7] in California worked with Syrian golden hamster-adapted scrapie where the incubation period was shorter than in the mouse and the amount of scrapie agent in clinical brain was at least tenfold greater. $\mathrm{He}$ came to the conclusion that the main component of the scrapie agent was a hydrophobic protein which polymerized easily. He coined the name 'prion' (proteinaceous infective particle) [7] and subsequently isolated protein from scrapie brain which he claimed was the major prion protein. Thus emerged the socalled 'protein-only hypothesis' for which Prusiner was awarded the Nobel prize in 1997.

Another characteristic of the scrapie agent has been the claim that it is partially resistant to breakdown to amino acids by proteolytic enzymes with no loss of infectivity being involved. It is true that it is largely resistant to the proteinase $\mathrm{K}$ which is a fungal enzyme much favoured by protein chemists and reference will be made to this later. This finding has been linked to the fact that in the transmission of BSE the active agent is not destroyed in the gastro-intestinal tract and rumen of sheep and cattle, and that the agent is resistant to the proteolytic enzymes therein. Against this is the fact that sheep and cattle are herbivores and may not be able to break down animal protein in the same way as carnivores, so this conclusion seems to be unproven. If so, it may be fortunate that man is an omnivore and it is possible that we may usually be able to break down the prion protein.

\section{The Structure of Prions}

The primary structure of the biologically active prion was determined and is given in figure 3 . This includes a signal peptide at the $\mathrm{N}$-terminus which is lacking in the mature protein. At the C-terminus there is a glycosylphosphatidylinositol (GPI) anchor which is used for attachment to the plasma membrane. The active prion which has an $\mathrm{M}_{\mathrm{r}}$ of 33-35 k is degraded by proteinase $\mathrm{K}$ to a protein with an $\mathrm{M}_{\mathrm{r}}$ of 27-30 k, as a result of the removal of some 60 amino acid residues. An oligonucleotide probe was synthesized to correspond to the N-terminus of this protein. This probe 
Fig. 3. Schematic representation of the 230-amino acid backbone of the human PrP protein showing sites of mutation associated with the occurrence of GSS at codons 102, 105, 117, 198 and 217. The signal peptide at the N-terminus is not present in the mature protein. At the C-terminus a 23-amino acid residue is replaced by a GPI membrane anchor labelled glycolipid. The octapeptide repeat region is shown with the normal five repeats. The different symbols involved the prediction of secondary structure before this was determined experimentally. From ref. 24.

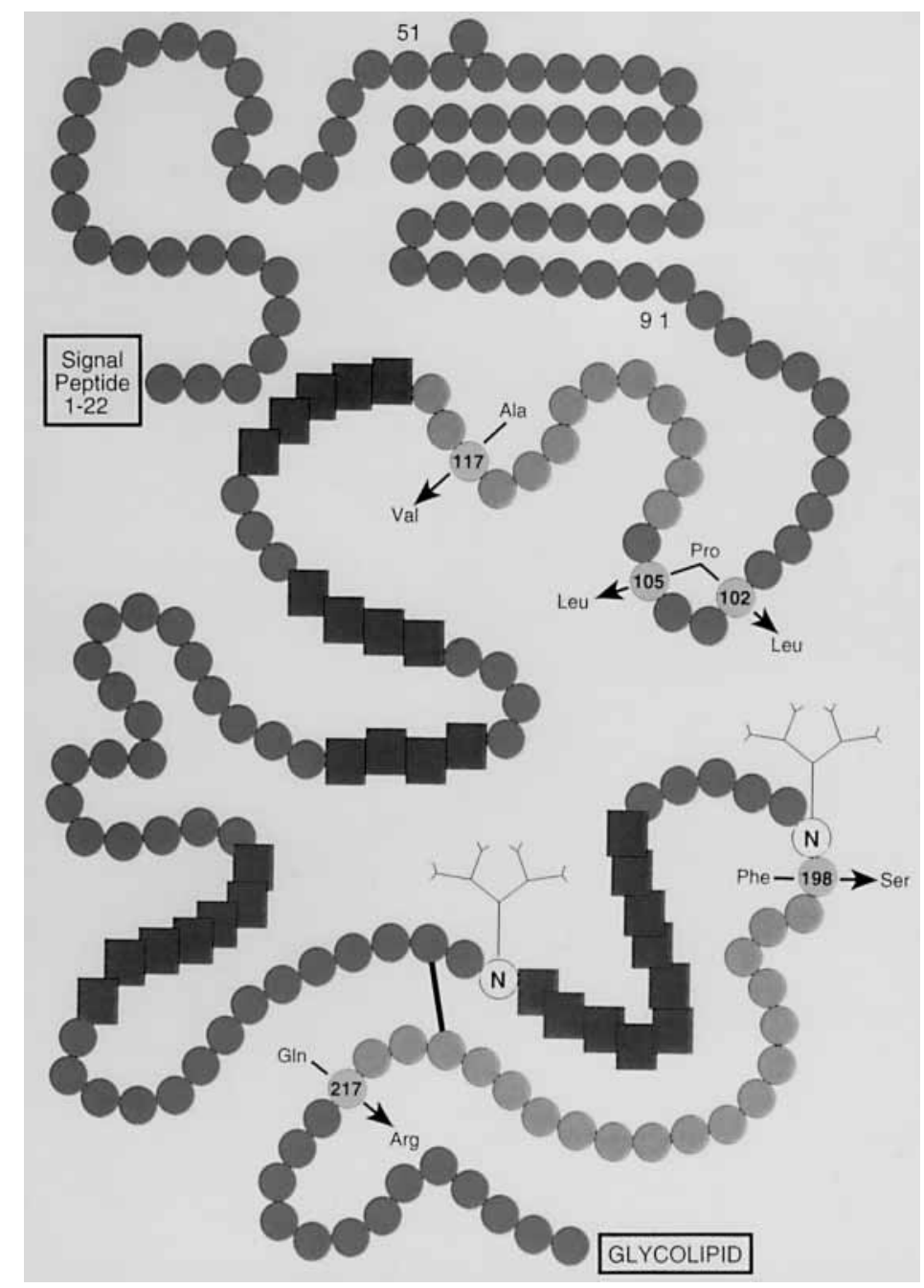

was used on the cDNA from hamster brain and an oligonucleotide for a $27-30 \mathrm{k}$ protein detected. Southern blotting gave a single gene with the same restriction patterns in normal and scrapie-infected brain DNA. Similar results were obtained in mice and humans where the gene concerned is located on the short arm of chromosome 20. PrP-related mRNA at similar levels was found in normal scrapie hamster brain and in many other nor- mal tissues. By the use of an antiserum against PrP 27-30 k, a PrP-related protein was detected in crude extracts of infected brain and to a lesser extent in normal brain. Proteinase $\mathrm{K}$ treatment yielded PrP 27-30 k in infected brain extracts, but the protein was completely degraded in normal brain. This established that there was a normal protein in many tissues which had the same properties as the biologically active prion except that it had no 

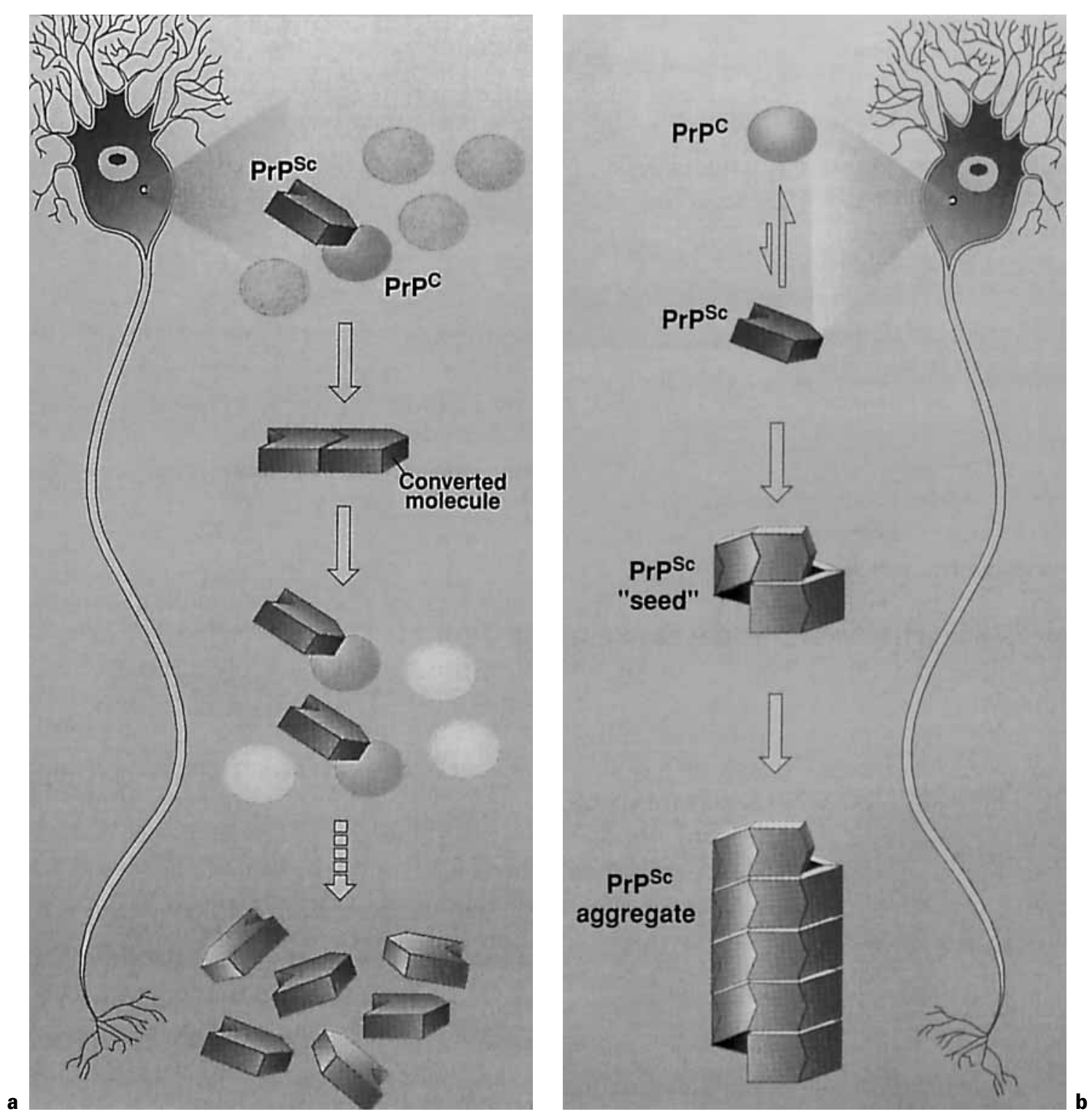

Fig. 4. Schemes for the conversion of $\operatorname{PrPC}^{\mathrm{C}}$ to $\mathrm{PrP}^{\mathrm{Sc}}$. a One hypothesis predicts that an abnormal protein $\mathrm{PrPSc}^{\mathrm{Sc}}$ contacts its normal twin $\mathrm{PrPC}^{\mathrm{C}}$ and changes it to an abnormal form. b An alternative hypothesis. In this a 'seed' is needed so that infection by $\mathrm{PrPSc}^{\mathrm{Sc}}$ seeds rapid polymerization of the molecules leading to self-replication of the infectious agent. After Mestel [25]. 
scrapie activity and was completely degraded by proteinase $\mathrm{K}$. The normal protein was designated $\mathrm{PrP}^{\mathrm{C}}$ while the scrapie form was designated $\mathrm{PrPSc}^{\mathrm{Sc}}$. I will use this nomenclature for the proteins involved in both scrapie and BSE.

\section{The Origin of the Infective Prion}

As a result of the above findings the concept arose that the active prion arose from a conversion of the normal $\mathrm{PrPC}^{\mathrm{C}}$ protein. This was confirmed when 'knockout' mice were produced that lacked the normal protein. These could not be infected with scrapie but infectivity was restored when $\operatorname{PrPC}^{\mathrm{C}}$ was reintroduced, the infectivity being greater in homozygotes than heterozygotes with respect to $\operatorname{PrPC}^{\mathrm{C}}$ [8]. Two schemes for the conversion of PrP have been put forward as shown in figure 4. In the first it is conjectured that there is some event which causes $\mathrm{PrPSc}$ to bind to $\operatorname{PrP}^{\mathrm{C}}$, and this sets off a cascade of conversion which generates lots of PrPSc. In the second, $\mathrm{PrPC}^{\mathrm{C}}$ and $\mathrm{PrPSc}^{\mathrm{Sc}}$ are in reversible equilibrium followed by an event, a seed, which involves $\mathrm{PrPSc}^{\mathrm{Sc}}$ binding to $\mathrm{PrP}^{\mathrm{C}}$ and a cascade results as in the process of crystallization. In analysing the conversion of $\mathrm{PrP}^{\mathrm{C}}$ to $\mathrm{PrP}^{\mathrm{Pc}}$ use is made of the increased resistance of $\mathrm{PrP}^{\mathrm{Ps}}$ to the action of proteinase $\mathrm{K}$.

\section{The Tertiary Structure of the Prions}

There has been an intense interest in the comparison of the structure of $\operatorname{PrPC}^{\mathrm{C}}$ and $\mathrm{PrPS}^{\mathrm{Sc}}$. Although they both have at least two glycosylation sites this does not account for the difference in resistance to proteinase $\mathrm{K}$ although there are some interesting aspects to which I will refer later. The carbohydrate moiety may play an important part in plaque formation in the brain. There is no difference in the primary structure of the two proteins so efforts have been directed to a comparison of the tertiary structures. Neither protein has

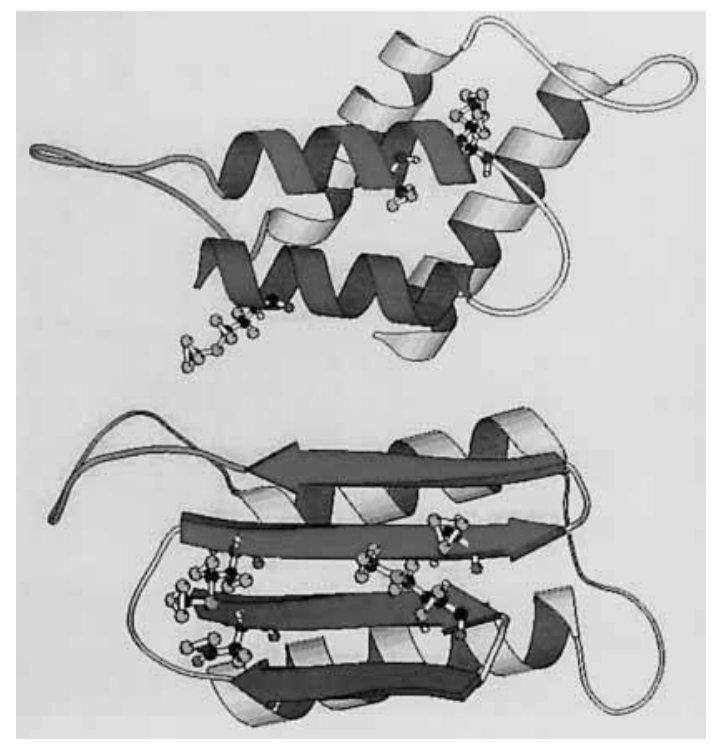

Fig. 5. Models for the tertiary structure of $\mathrm{PrPSc}^{\mathrm{Sc}}$ on the left and $\mathrm{PrP}^{\mathrm{Pc}}$ on the right. After Mestel [25].

been crystallized so this work has centred on NMR and physical measurements such as Fourier-transform infrared and circular dichroism. A model of the structure of $\mathrm{PrP}^{\mathrm{C}}$ is shown in figure 5. It is difficult to produce a model of $\mathrm{PrP}^{\mathrm{Sc}}$ for the protein is insoluble and although it can be denatured it then loses its infectivity. However, it is possible to estimate the content of $\alpha$-helix and $\beta$-sheet in the two forms. $\operatorname{PrP}^{\mathrm{C}}$ has $43 \% \alpha$-helix and $3 \% \beta$-sheet compared with $34 \% \alpha$-helix and $43 \% \beta$-sheet for PrPSc. Based on these results a model for $\mathrm{PrPSc}^{\mathrm{Sc}}$ has been produced and is shown in figure 5. It is conjectured that the extra content of $\beta$-sheet is in accord with its greater resistance to proteinase $\mathrm{K}$. The complete tertiary structure of $\operatorname{PrP}^{\mathrm{C}}$ has been determined by NMR and is shown in figure 6 [9]. This is in close accord with the model and shows that there is a large random coil chain at the $\mathrm{N}$ terminus. It is possible that it is this random coil that is converted into a $\beta$-sheet in $\mathrm{PrP}^{\mathrm{Sc}}$. 
Fig. 6. The tertiary structure of mature murine $\operatorname{PrP} \mathrm{mPrP}(23-231)$ produced from rDNA in Escherichia coli as determined by NMR. The dots represent the 98 residues of the N-terminal segment 23-120 which shows features of a flexible 'random-coil-like' polypeptide. From Riek et al. [8].

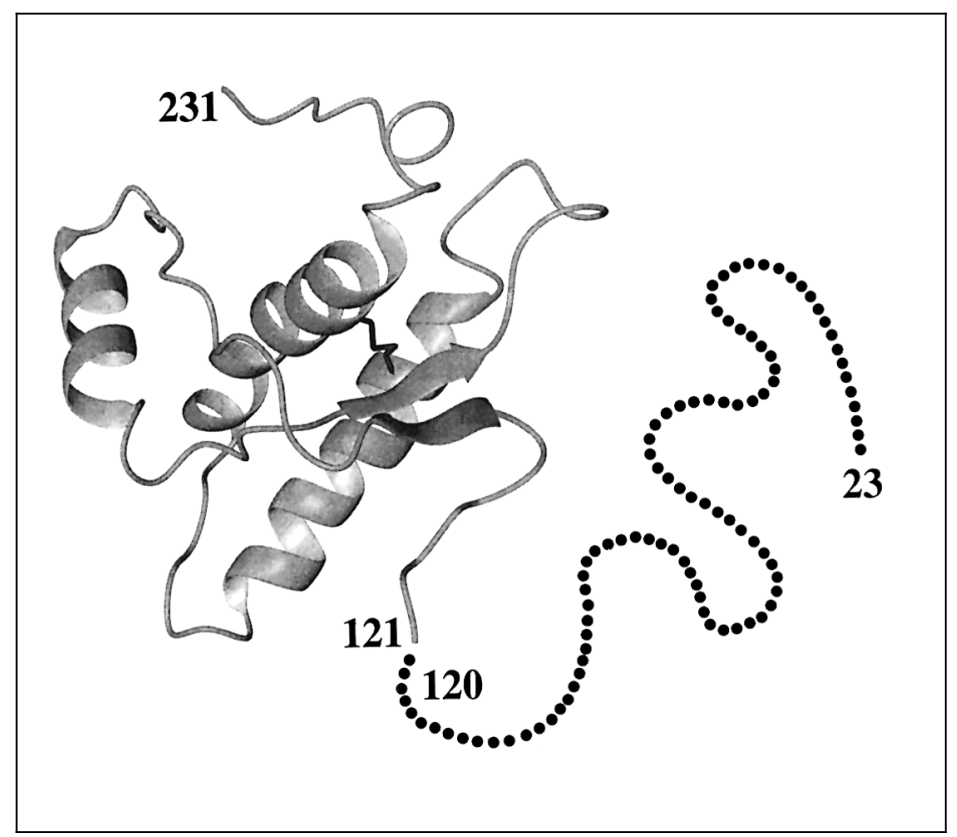

Model systems for the conversion of proteins with similar properties to those described above have been devised using both animal extracts [10] and yeast [11]. So it has been said that prions are not unique to animals. These may indeed be useful model systems but care should be exercised in the use of the word prion if all that is measured is merely the conversion to a proteinase-resistant protein and biological activity is not involved. The fact that the primary structure is not the sole criterion for determining protein tertiary structure came as something of a surprise when molecular chaperones were discovered. It is not surprising, therefore, that there is evidence that another protein, protein $\mathrm{X}$ in the nomenclature of Prusiner [12], is involved in the conversion to $\mathrm{PrP}^{\mathrm{Sc}}$ [13], but it is not clear as yet whether a chaperone is involved. In any event it is not possible to be sure that $\mathrm{PrPSc}$ is responsible per se for the infectivity for the renatured protein after treatment with dena- turation agents is not active, nor is that synthesized from recombinant rDNA. In summary, it has not so far been possible under in vitro conditions to convert $\operatorname{PrPC}^{\mathrm{C}}$ to a form that possesses infectivity. There are other worrying aspects of the so-called protein only hypothesis to which I will return to later.

\section{The Effect of Mutations and}

\section{Polymorphism of Prions}

A lot of work has been done on the effect of mutations in $\mathrm{PrP}^{\mathrm{C}}$, in the incidence of CJD. There is no doubt that familial CJD is associated with certain mutations and in sporadic CJD they make some difference to susceptibility, but space limits further discussion of this matter [14]. Of more significance is the effect of polymorphisms in $\operatorname{PrP}^{\mathrm{C}}$, particularly that at position 129 , which can be occupied by either Met or Val. Patients can be homozygous for either Met or Val at this position. All the cases of nvCJD so far found are homozy- 
gous for Met-29, and this is also the most common genotype amongst sporadic cases of CJD.

\section{The Glycoforms of the Prions}

If $\mathrm{PrPSc}$ is isolated and treated with proteinase $\mathrm{K}$ and an antiserum is used for a Western blot after electrophoresis then three bands are obtained. The two major bands are glycosylated proteins, glycosylated to different extents with sialic acid, and the fastest band is unglycosylated. The rate of migration of the proteins on the gel is also influenced by the polymorphism at position 129 already described. Collinge et al. [15] examined the results of such a procedure on the $\mathrm{PrPSc}^{\mathrm{Ob}}$ tained after infection of mice under various conditions. The first results were published in July 1996 and were confirmed later. Figure 7 summarises the results. These show that the pattern on electrophoresis (called a signature) differs between scrapie and BSE and that the nvCJD patients clearly had an infection which was characteristic of BSE. This was the first such result to back up the conclusions concerning the origin of nvCJD which had previously depended on the pathology of the brain [15-17]. The work of Collinge et al. [15] implicating BSE as the cause of nvCJD was supported by the transmission of BSE to Macaque monkeys which produced a neuropathology very similar to nvCJD [18].

\section{Strains of Scrapie and BSE}

During the extensive work on scrapie in sheep it became apparent that there were many strains of the disease. These were defined in terms of the length of incubation, the behaviour of the animal and the pathology of the brain. As many as 20 strains have been so defined. In a similar manner the CJD surveillance group at Edinburgh has characterised all the cases of BSE both in humans and animals and has confirmed that all the parameters for the emergence of nvCJD bear the hallmarks of BSE [19].

If the protein-only hypothesis for the infective agent is correct then the infectivity depends on the transmogrification of $\mathrm{PrPC}^{\mathrm{C}}$ to produce a specific tertiary structure of $\mathrm{PrPSc}^{\mathrm{Sc}}$ so that it is argued that the presence of different strains of either scrapie or BSE implies that there must be various structures of PrPSc. It has now been shown that experimentally sheep may be infected with BSE and so the same $\operatorname{PrPC}^{\mathrm{C}}$ must be capable of transmogrification into different structures characteristic of either scrapie or BSE. What is more, these specific PrP structures are transferred to the animal's progeny, for the strains are genetically stable. With our present knowledge of protein structure and genetics it is hard to understand how this can be so. The results of the polymorphisms of CJD and the fact that all cases of nvCJD are homozygous for Met-129 suggests that such polymorphisms have an influence on the ease of conversion of $\mathrm{PrPC}^{\mathrm{C}}$ to PrPSc.

\section{The Production of a Monoclonal Antibody to PrPSc}

A more recent development is the production by the Zurich group of a monoclonal antibody which can discriminate between the normal and disease-specific forms of PrP [20]. PrP-null mice were immunized with recombinant bovine PrP and a monoclonal antibody, $15 \mathrm{~B} 3$, which was isolated, specifically reacted with bovine, murine or human $\operatorname{PrPSc}^{\mathrm{S}}$ but not $\mathrm{PrPC}^{\mathrm{C}}$, suggesting that it recognizes an epitope common to prions from different species. They also mapped three polypeptide segments in PrP as the 15B3 epitope. Hopefully by the use of such an antibody ultimately it will be possible to detect the presence of $\mathrm{PrP}^{\mathrm{BSE}}$ in cattle before they show clinical symptoms of BSE. There are claims that patients who are developing CJD may have a 


\section{Wild-type mice}

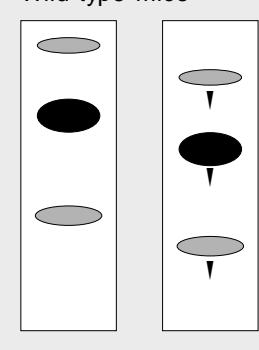

Type 1

$\uparrow$

Primary human brain extracts

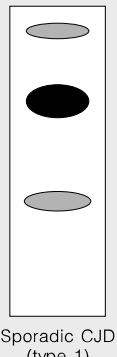

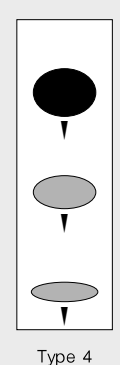

$\uparrow$

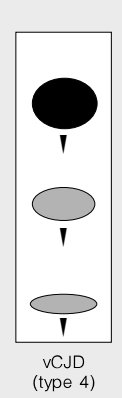

(type 3)
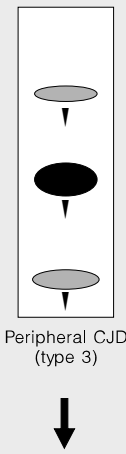

Humanized transgenic mice $\left(129^{\mathrm{Val}}\right.$
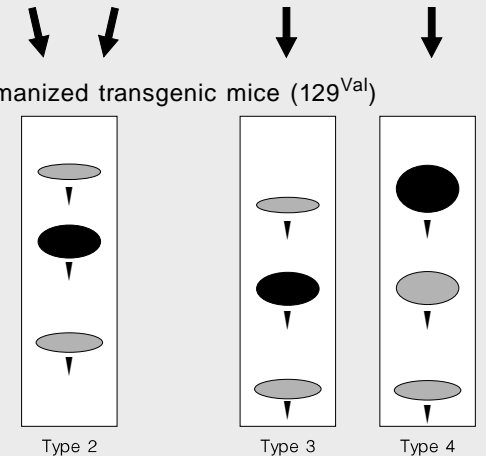
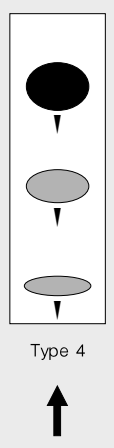

Primary animal brain extracts

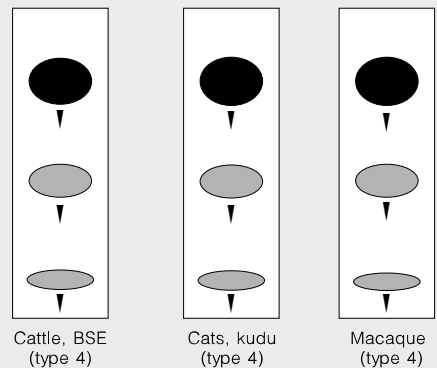

Fig. 7. The glycoforms of prions. Western blots of different prion strains show characteristic patterns of $\mathrm{PrP}^{\mathrm{Sc}}$ glycoforms which are inherited even when the infectious agent is passed within different species. The large arrows indicate successful transmissions. The major glycoform is shown in black and the little arrows on the Western blots indicate increased mobility compared with type 1 . The humanized transgenic mice were transgenic for the human PrP gene. From Aguzzi and Weissmann [17]. 
brain protein in their serum before the disease is confirmed by pathology. This also would be useful.

\section{The Future}

It will be seen that while the actual epidemic of BSE in the $\mathrm{UK}$ is rapidly receding it has left many footprints particularly in terms of the possible epidemic of nvCJD. Biochemists find it difficult to accept that prion diseases are caused solely by the prion protein and many remain attracted to the concept that a nucleic acid must be involved. It is true that conclusive proof for the protein-only hypothesis has eluded us but against this is the fact that no one has yet identified the involvement of a nucleic acid. Another concern is that although mice injected with an extract from BSE-infected cattle brain exhibited neurological symptoms and neuronal death, more than 55\% had no detectable PrPBSE. During serial passage PrPBSE appeared after the agent adapted to the new host [21]. This supports the view that while prions are involved in infectivity other agents also play a part. This view is supported by the fact that the ratio of PrPsc molecules to infection units is only about 1:100,000, but there is evidence that the mouse assay is very insensitive when compared with the sensitivity of calves who may succumb to as little as $1 \mathrm{~g}$ of an extract from the brains of BSE-infected cattle. We also know little about the way in which amyloid is formed and virtually nothing about the resulting striking pathology. Thus there is much work remaining concerning the fundamental science as has been pointed out in two recent articles [22, 23].

In terms of animal husbandry it seems clear that more care must in future be taken concerning the make-up of animal feedstocks. The general public has been shocked about many of the practices that have recently come to light. It is also clear that it is unacceptable for a country like the UK to continue to tolerate the presence of a disease like scrapie in the animals used for food even though it appeared to be harmless to man. In this case the funds for research were not available from industry, for the profit motive could not sustain such expenditure so such research had to depend on government support which in the event was parsimonious. The enormous cost of the compensation for the slaughter of cattle in the case of BSE is a reminder of the results of such parsimony.

Various therapies have been suggested, not only because of the fear of the emergence of an epidemic of nvCJD but also because it is hard to accept that prion diseases are confined to transmissible encephalopathies. One concerns the role of normal PrPC. If it has no physiological role then it has been suggested that it might be a good idea by genetic manipulation to rear cattle and sheep lacking $\mathrm{PrPC}$ but the cost of such a programme is daunting even if it were possible. Another route is to produce drugs which would inhibit the transmogrification of $\mathrm{PrP}^{\mathrm{C}}$ to an infective form. In this respect the model systems in yeast and bacteria that are being studied are particularly relevant. 


\section{References}

1 Hunter GD: Scrapie and Mad Cow Disease. New York, Vantage Press, 1993.

2 Prusiner SB (ed): Prions Prions Prions. Heidelberg, Springer, 1996.

3 Update on BSE. London, Royal Society, 1997.

4 Smith C, Collinge J: Molecular pathology of prion disease. Essays Biochem 1995;29:157-174.

5 Donnelly CA, Ghani AC, Ferguson NM, Anderson RM: Recent trends in the BSE epidemic. Nature 1997; 389:903.

6 Klein MA, et al: A crucial role for B cells in neuroinvasive scrapie. $\mathrm{Na}$ ture 1997;390:687-690.

7 Prusiner SB: Novel proteinaceous infectious particles cause scrapie. Science 1982;216:136-144.

8 Bueler H, et al: Mice devoid of PrP are resistant to scrapie. Cell 1993; 73:1339-1347.

9 Riek R, Hornemann S, Wider G, Glockshuber R, Wuthrich K: NMR characterization of the full-length recombinant murine prion protein, mPrP (23-231). FEBS Lett 1997; 413:282-288.

10 Raymond GJ, et al: Molecular assessment of the potential transmissibilities of BSE and scrapie to humans. Nature 1997;388:285-288.
11 Paushkin SV, et al: in vitro propagation of the prion like state of yeast Sup35 protein. Science 1997;277: 381-383.

12 Prusiner SB: Prion diseases and the BSE crisis. Science 1997;278:245251.

13 Hegde RS, et al: A transmembrane form of the prion protein in neurodegenerative disease. Science 1998; 279:827-834.

14 Parchi P, et al: Molecular basis of phenotypic variability in sporadic Creutzfeldt-Jakob disease. Ann Neurol 1996;39:767-778.

15 Collinge J, Sidle KCL, Meads J, Ironside J, Hill AF: Molecular analysis of prion strain variation and the aetiology of 'new variant' CJD. Nature 1996;383:685-690.

16 Hill AF, et al: The same prion strain causes VCJD and BSE. Nature 1997; 389:448-450.

17 Aguzzi A, Weissmann C: A suspicious signature. Nature 1996;383. 666-667.

18 Lasmezas CI, et al: BSE transmission to macaques. Nature $1996 ; 381$ : 743-744.

19 Bruce ME, et al: Transmissions to mice indicate that 'new variant' CJD is caused by the BSE agent. Nature 1997;389:498-501.
20 Korth $\mathrm{C}$, et al: Prion ( $\mathrm{PrPSc}^{\mathrm{Sc}}$-specific epitope defined by a monoclonal antibody. Nature 1997;390:74-77.

21 Lasmezas CI, et al: Transmission of the BSE agent to mice in the absence of detectable abnormal prion protein. Science 1997;275:402-405.

22 Aguzzi A, Weissmann C: Prion research: The next frontiers. Nature 1997;389:795-798.

23 Chesebro B: BSE and prions: Uncertainties about the agent. Science 1998;279:42-43.

24 Transmissible Spongiform Encephalopathies: A Summary of Present Knowledge and Research. London, HMSO, 1994, p 50.

25 Mestel R: Putting prions to the test (news). Science 1996;273:184-189.

\section{Note Added in Proof}

The total of nvCJD cases is now 25 (June 1998). 